\title{
Regulator of Calcineurin 1 (Rcan1) Is Required for the Development of Pulmonary Eosinophilia in Allergic Inflammation in Mice
}

\author{
Yong Jun Yang, ${ }^{*}$ Adam J. MacNeil, ${ }^{\dagger \neq}$ \\ Robert Junkins, ${ }^{\dagger \neq}$ Svetlana O. Carrigan, ${ }^{\text {}}{ }^{\ddagger}$ \\ Jin-Tian Tang, ${ }^{\S}$ Nicholas Forward, ${ }^{\dagger \neq}$ \\ David Hoskin, ${ }^{\dagger \ddagger}$ Jason N. Berman, ${ }^{\dagger \neq}$ \\ and Tong-Jun Lin ${ }^{\dagger \ddagger}$

\begin{abstract}
From the Institute of Zoonosis," College of Animal Sciences and Veterinary Medicine, Jilin University, Changchun, China; the Departments of Microbiology and Immunology ${ }^{\dagger}$ and Pediatrics, ${ }^{\neq}$ Dalhousie University, Halifax, Nova Scotia, Canada; and the Institute of Medical Physics and Engineering, ${ }^{5}$ Tsinghua
\end{abstract} \\ University, Beijing, China
}

\begin{abstract}
The presence of eosinophils in the lung is often regarded as a defining feature of asthma. On allergen stimulation, numbers of eosinophils and their progenitors are increased in both the bone marrow and lungs. Eosinophil progenitors provide an ongoing supply of mature eosinophils. Here, we report that deficiency in the regulator of calcineurin 1 gene (Rcan1) leads to a near-complete absence of eosinophilia in ovalbumin-induced allergic asthma in mice. In the absence of Rcan1, bone marrow cells produce significantly fewer eosinophils in vivo and in vitro on interleukin-5 stimulation. Importantly, eosinophil progenitor populations are significantly reduced in both naive and ovalbumin-challenged Rcan1 $^{-/-}$ mice. Bone marrow cells from Rcan $^{-/-}$mice are capable of developing into fully mature eosinophils, suggesting that Rcan 1 is required for eosinophil progenitor production but may not be necessary for eosinophil maturation. Thus, Rcan1 represents a novel contributor in the development of eosinophilia in allergic asthma through regulation of eosinophil progenitor production. (Am J Pathol 2011, 179:1199-1210; DOI: 10.1016/j.ajpath.2011.05.022)
\end{abstract}

A nationwide survey found that more than half (54.6\%) of the U.S. population test positive to one or more allergens. ${ }^{1}$ Allergic asthma is a chronic inflammatory disease that is characterized by eosinophil infiltration. Eosinophils are prominent effector cells in allergic asthma. ${ }^{2-4}$ Several studies have established a causative link between eosinophils and allergic lung diseases. ${ }^{5-8}$ Targeting eosinophils using anti-IL-5 antibodies has been considered as a therapeutic approach for the treatment of asthma. In steady state, eosinophil progenitors constantly egress from the bone marrow into the blood and circulate to peripheral tissues. In allergic diseases, the bone marrow releases increased numbers of eosinophil progenitor cells that migrate to the site of allergic inflammation, where they provide a constant supply of mature eosinophils. ${ }^{9-13}$ Molecular mechanisms governing eosinophil progenitor production remain incompletely defined.

Down syndrome patients who overexpress regulator of calcineurin 1 (Rcan1) have an association with immune disorders including allergy and asthma. ${ }^{14-16}$ Hypereosinophilic syndrome was reported in a fetus harboring trisomy 21. ${ }^{17}$ Eosinophilic pericardial effusion was also documented in a neonate with Down syndrome. ${ }^{18}$ The proform of eosinophil major basic protein has been identified as a maternal serum marker for Down syndrome. ${ }^{19}$ Increased incidence of allergic asthma in patients with Down syndrome has been reported in a recent large survey study. ${ }^{15}$ These findings suggest an association of Rcan1 with eosinophils and asthma.

The human RCAN1 gene was previously known as DSCR1 (Down syndrome critical region 1). ${ }^{20}$ Additional names for Rcan1 include Adapt78 (the gene is transiently induced during cell adaptation), ${ }^{21}$ myocyte-enriched calcineurin interacting protein 1 (MCIP1), ${ }^{22}$ calcipressin $1,{ }^{23}$ and calcineurin binding protein 1 (CBP1). ${ }^{24}$ The human RCAN1 gene is located on chromosome 21. Rcan1 is widely expressed in various tissues, including heart, lung, kidney, brain, muscle, liver, and testis. ${ }^{22,25,26}$ The RCAN1 gene

Supported by grants from the Canadian Institutes of Health Research and Izaak Walton Killam Health Center (T.-J.L.).

Accepted for publication May 9, 2011.

Supplemental material for this article can be found at http://ajp. amjpathol.org or at doi: 10.1016/j.ajpath.2011.05.022.

Address reprint requests to Tong-Jun Lin, Ph.D., Izaac Walton Killam Health Center, Department of Pediatrics, 5850 University Ave., Halifax, NS, B3K 6R8 Canada. E-mail: tong-jun.lin@dal.ca. 
consists of seven exons, of which exons 1 to 4 can be alternatively transcribed. ${ }^{27}$ Deletion of exons 5 and 6 from the mouse Rcan 1 gene leads to deficiency of the Rcan1 protein. ${ }^{28}$ These $R$ Rcan $^{-1-}$ mice are viable and fertile and provide a useful tool for the study of Rcan1 function. ${ }^{28}$

Published reports on Rcan1 function are concerned largely with calcineurin activity. Experiments in different organisms and cell types have showed a dual function for Rcan1, which can act as either an inhibitor ${ }^{29,30}$ or a facilitator ${ }^{24,28,31-33}$ of calcineurin activity, depending on the cellular context. In yeast and in Cryptococcus neoformans, Rcan1 has the characteristics of a calcineurin activator, ${ }^{24,32,33}$ and in a cardiac hypertrophic mouse model Rcan1 functions as a calcineurin facilitator. ${ }^{28,31}$ In contrast, in other experimental models, Rcan1 inhibits calcineurin activity in vitro and in vivo. ${ }^{23,29,30}$ Recently, we found that Rcan1 is an inhibitor of calcineurin in mast cells. ${ }^{34}$

Our finding that Rcan1 is a negative regulator of IgEmediated mast cell activation ${ }^{34}$ prompted us to determine what role Rcan1 has in allergic asthma. Surprisingly, we found that Rcan 1 deficiency leads to near-complete absence of eosinophilia in ovalbumin-induced asthma in mice. The number of eosinophil progenitors was significantly reduced in $R \mathrm{Rcan}^{1^{-1-}}$ mice, and calcineurin activity was reduced in $R c a n 1^{-/-}$eosinophil progenitors. Thus, Rcan1 represents a novel mechanism in the development of eosinophilia in allergic asthma, likely by regulating eosinophil progenitor cell numbers.

\section{Materials and Methods}

\section{Animals}

The Rcan 1 gene was targeted for deletion by standard homologous recombination in embryonic stem cells (Sv129 strain), followed by generation of chimeric mice, which were subsequently bred to pass the targeted allele into the germline in the C57BL/6 genetic background, as described elsewhere. ${ }^{28}$ These mice were originally provided by Dr. Jeffery Molkentin (Cincinnati Children's Hospital Medical Center, University of Cincinnati, Cincinnati, $\mathrm{OH})$. The protocols were approved by the University Committee on Laboratory Animals, Dalhousie University, in accordance with guidelines of the Canadian Council on Animal Care.

\section{Antibodies}

Antibodies to phospho-JNK (Thr 183/Tyr 185), JNK, phospho-p38 MAPK (Thr 180/Tyr 182), phospho-Stat5, Stat5, phospho-p44/42, p44/42, phospho-Gsk3 $\beta$, and Gsk3 $\beta$ were purchased from Cell Signaling Technology (Danvers, MA). Antibodies to p38 MAPK and actin were purchased from Santa Cruz Biotechnology (Santa Cruz, CA). Antibody to GATA-1 was purchased from Novus Biologicals (Littleton, CO). Fluorescein isothiocyanate (FITC)-conjugated rat anti-mouse CD117 (c-kit) monoclonal antibody and FITC-rat IgG2a were purchased from Cedarlane Laboratories (Hornby, ON, Canada). FITCconjugated rat anti-mouse IgE (IgG1) and FITC-rat IgG1 were purchased from BD Biosciences (San Jose, CA).

\section{Allergen Sensitization and Challenge}

Mice were immunized intraperitoneally with $10 \mu \mathrm{g}$ ovalbumin (OVA) (grade V; Sigma-Aldrich, St. Louis, MO) in $0.1 \mathrm{~mL}$ saline on days $0,2,4,6,8,10$, and 12 . On days 40,43 , and 46 , mice were challenged intranasally with $200 \mu \mathrm{g}$ OVA (20 $\mu \mathrm{L}$ of $10 \mathrm{mg} / \mathrm{mL}$ ) in saline or with saline alone.

\section{Bronchoalveolar Lavage, Lung Tissue Processing, and Histology}

Bronchoalveolar lavage fluid (BALF) was obtained by lavaging the lung with $1 \mathrm{~mL}$ of phosphate buffer solution containing soybean trypsin inhibitor $(100 \mu \mathrm{g} / \mathrm{mL})$. The BALF was centrifuged and the supernatants were stored at $-80^{\circ} \mathrm{C}$ until use. Cell pellets were resuspended in $1 \mathrm{~mL}$ of PBS. The BALF cells were counted, cytospun, and stained using a Diff-Quik assay (Fisher Scientific, Pittsburgh, PA). At least 200 cells per slide were examined and were characterized as mononuclear cells, neutrophils, or eosinophils. The remaining cells were homogenized in $250 \mu \mathrm{L}$ of $0.5 \%$ cetyltrimethylammonium chloride and centrifuged at $4^{\circ} \mathrm{C}$ for 30 minutes at $16,000 \times g$. The supernatants were used for eosinophil peroxidase (EPO) and myeloperoxidase (MPO) assay.

The right lung was homogenized (at maximum speed for 20 seconds; PowerGen 125; Fisher Scientific) in 50 $\mathrm{mmol} / \mathrm{L}$ HEPES buffer ( $4 \mu \mathrm{L} / \mathrm{mg}$ lung) containing soybean trypsin inhibitor $(100 \mu \mathrm{g} / \mathrm{mL})$. The homogenate was centrifuged at $4^{\circ} \mathrm{C}$ for 30 minutes at $16,000 \times \mathrm{g}$. The supernatant was stored at $-80^{\circ} \mathrm{C}$ for later cytokine analysis. The pellet was resuspended and homogenized in 0.5\% cetyltrimethylammonium chloride (4 $\mu \mathrm{L} / \mathrm{mg}$ lung) and centrifuged as described above. The clear extract was used for EPO and MPO assays. One third of the left lung was excised and fixed in $10 \%$ formalin overnight and then in $100 \%$ ethanol for paraffin embedding and sectioning. Slides were subjected to staining with H\&E or PAS.

\section{ELISA and Cytokine Multiplex Assay}

Cytokines in the cell-free supernatants were determined using DuoSet ELISA kits obtained from R\&D Systems (Minneapolis, MN). Cell-free culture supernatants were also analyzed for cytokines using a Bio-Plex Pro mouse 23-plex group 1 cytokine assay (Bio-Rad, Hercules, CA), which detects 23 cytokines and chemokines. The assay was performed according to the manufacturer's protocol and was read on a Bio-Plex 200 HTF multiplex array system. Data were analyzed using Bio-Plex Manager version 6.0 software (Bio-Rad).

\section{MPO and EPO Assay}

Myeloperoxidase activity in the lung was determined as a marker for neutrophils. Briefly, samples in duplicate (75 $\mu \mathrm{L}$ ) were mixed with equal volumes of the substrates (3 $\mathrm{mmol} / \mathrm{L}$ 3,3',5,5'-tetramethylbenzidine dihydrochloride, $120 \mu \mathrm{mol} / \mathrm{L}$ resorcinol, and $2.2 \mathrm{mmol} / \mathrm{L} \mathrm{H}_{2} \mathrm{O}_{2}$ ) for $2 \mathrm{~min}$ utes. The reaction was stopped by adding $150 \mu \mathrm{L}$ of 2 $\mathrm{mol} / \mathrm{L} \mathrm{H}_{2} \mathrm{SO}_{4}$. The optical density was measured at 450 
$\mathrm{nm}$. For EPO assay, $75 \mu \mathrm{L}$ of substrate solution ( $3 \mathrm{mmol} / \mathrm{L}$ o-phenylenediamine dihydrochloride, $50 \mathrm{mmol} / \mathrm{L}$ chloride-free HEPES pH 8.0, $6 \mathrm{mmol} / \mathrm{L} \mathrm{KBr}$, and $8.8 \mathrm{mmol} / \mathrm{L}$ $\mathrm{H}_{2} \mathrm{O}_{2}$ ) was added to $75 \mu \mathrm{L}$ of each sample. After 30 minutes, the reaction was stopped with $150 \mu \mathrm{L}$ of $2 \mathrm{~mol} / \mathrm{L}$ $\mathrm{H}_{2} \mathrm{SO}_{4}$ and the absorbance was read at $490 \mathrm{~nm}$.

\section{Fluorescence-Activated Cell Sorting Analysis and Sorting of Eosinophil Lineage-Committed Progenitors}

Eosinophil progenitor cells were analyzed or sorted according to published protocols. ${ }^{35}$ Briefly, bone marrow cells were stained with antibodies to the IL-5R $\alpha$ chain, c-Kit, CD34, and Sca-1, as well as a lineage cocktail including antibodies to CD3, CD4, CD8, B220, Gr-1, and $\mathrm{CD} 19$. Eosinophil progenitors were identified as $\mathrm{Lin}^{-} \mathrm{Sca}-$ $1^{-} \mathrm{CD} 34^{+} \mathrm{IL}-5 \mathrm{R} \alpha^{+} \mathrm{c}-\mathrm{Kit}{ }^{\mathrm{low}}$ cells. Mature eosinophils were defined as Siglec- $\mathrm{F}^{+}$or Siglec- $\mathrm{F}^{+} \mathrm{IL}-5 \mathrm{R} \alpha^{+}$cells. In some experiments, to acquire bone marrow cells containing eosinophil progenitors (for Western blot analysis, realtime PCR, or calcineurin activity assay), bone marrow cells were stained with antibodies to CD34, Sca-1, and lineage markers (CD3, CD4, CD8, B220, Gr-1, and CD19). CD34 ${ }^{+} \mathrm{Lin}^{-}$Sca- $1^{-}$and CD34 ${ }^{-} \mathrm{Lin}^{-} \mathrm{Sca}-1^{-}$bone marrow cells were obtained by cell sorting.

The following antibodies were purchased from BD Biosciences: PE-CD3, PE-CD4, PE-CD8, PE-B220, PE-Gr-1, PE-CD19, PE-Sca-1, Alexa Fluor 488-IL-5R $\alpha$ chain, PerCPCy5.5-c-Kit, Alexa Fluor 647-CD34, and PE-Siglec-F.

\section{Colony-Forming Assay}

Bone marrow cells were collected by flushing the tibia of wild-type and $R \mathrm{Can}^{-1-}$ mice. The erythrocytes were removed by lysis using $\mathrm{NH}_{4} \mathrm{Cl}$. Bone marrow cells $\left(9 \times 10^{3}\right.$ cells) were cultured in Methocult GF3434 methylcellulose medium (StemCell Technologies, Vancouver, BC, Canada) containing $50 \mathrm{ng} / \mathrm{mL}$ of IL-5. On day 12 , the numbers of colonies were counted microscopically.

\section{IL-5-Induced Eosinophil Production in Vivo}

Recombinant murine IL-5 (rmlL-5, $10 \mu \mathrm{g} /$ day; PeproTech, Rocky Hill, NJ) was injected intraperitoneally into wildtype and $R$ can $^{-1-}$ mice for 6 days (days 0 to 5). Differential counts were performed by examination of blood smears stained with Diff-Quik at various time points.

\section{Bone Marrow-Derived Eosinophil Isolation and Culture}

Mouse primary bone marrow-derived eosinophils were cultured as described elsewhere. ${ }^{36}$ Bone marrow cells were collected from the femurs and tibiae of wild-type and $R$ can $^{-1-}$ mice. Red blood cells were lysed in $\mathrm{H}_{2} \mathrm{O}$ for 15 seconds followed by the addition of $2 \times$ phosphate buffer. The bone marrow cells were cultured at $1 \times 10^{6}$ cells/mL in RPMI 1640 medium (Invitrogen, Carlsbad, CA) supplemented with $10 \%$ fetal bovine serum, $100 \mathrm{IU} / \mathrm{mL}$ pen- icillin, $10 \mu \mathrm{g} / \mathrm{mL}$ streptomycin, $25 \mathrm{mmol} / \mathrm{L}$ HEPES (Invitrogen), $50 \mu \mathrm{mol} / \mathrm{L}$ 2-mercaptoethanol (Sigma-Aldrich), 100 $\mathrm{ng} / \mathrm{mL}$ recombinant murine stem cell factor (rmSCF; PeproTech), and $100 \mathrm{ng} / \mathrm{mL}$ recombinant murine FLT3 ligand (rmFLT3-L; PeproTech) from days 0 to 4 . On day 4, the medium containing SCF and FLT3-L was replaced with medium containing $50 \mathrm{ng} / \mathrm{mL} \mathrm{rmlL}-5$ only. On day 8 , the cells were moved to new flasks and maintained in fresh medium supplemented with rmIL-5.

\section{Chemotaxis Assay}

The assay was performed in a 24-well Transwell plate (Corning Life Sciences, Corning, NY) with a 5.0- $\mu \mathrm{m}$ pore size polycarbonate membrane. The medium $(600 \mu \mathrm{L})$ containing $50 \mathrm{ng} / \mathrm{mL} \mathrm{rmlL}-5$ was placed in the lower chamber. Recombinant mouse eotaxin (rmEotaxin; PeproTech) was added to the lower chamber as a chemoattractant. Bone marrow-derived eosinophils in $100 \mu \mathrm{L}\left(2 \times 10^{6} \mathrm{cells} / \mathrm{mL}\right)$ were placed in the upper chamber. Cells were incubated for 60 minutes at $37^{\circ} \mathrm{C}$ to permit migration across the membrane. The Transwell inserts were gently removed, and the cells in the bottom wells were counted.

\section{Real-Time Quantitative PCR}

The mRNA levels of Rcan 1 and GATA-1 were quantified using Assays-on-Demand reagents containing TaqMan MGB probes and TaqMan master mix (Applied Biosystems, Foster City, CA) on a sequence detection system (ABI Prism 7000, Applied Biosystems). GAPDH was used as an endogenous reference. The Assays-on-Demand reagents for Rcan1 target the larger Rcan1 isoform (Rcan1-1). Data were analyzed using the relative standard curve method according to the manufacturer's protocol. A mean value of target gene after GAPDH normalization at the time point showing highest expression was used as a calibrator to determine the relative levels of Rcan 1 at different conditions. PCR products were resolved on a $2 \%$ agarose gel and were stained with ethidium bromide (Invitrogen, Carsbad, CA).

\section{Calcineurin Activity Assay}

Phosphatase activity was measured using a calcineurin assay kit (Biomol International-Enzo Life Sciences, Plymouth Meeting, PA). To obtain the eosinophil progenitor cell population, bone marrow cells from wild-type and Rcan $1^{-1-}$ mice were incubated with antibodies to CD34 and Sca-1 and with a lineage cocktail including antibodies to CD3, CD4, CD8, B220, Gr-1, and CD19. CD34 ${ }^{+} \mathrm{Lin}^{-}$Sca- $1^{-}$cells were obtained by cell sorting. Lysates were prepared from CD34 ${ }^{+} \mathrm{Lin}^{-} \mathrm{Sca}-1^{-}$bone marrow cells or mature eosinophils cultured from bone marrow cells. Phosphatase activity was measured according to the manufacturer's instructions.

\section{Western Blot Analysis}

Cell lysates (20 to $30 \mu \mathrm{g}$ ) were subjected to electrophoresis in $12 \%$ SDS-polyacrylamide gels. Gels were trans- 
ferred to polyvinylidene difluoride membrane, blotted with primary and secondary antibodies, and detected by an enhanced chemiluminescence detection system (Western Lightning Plus-ECL; PerkinElmer, Norwalk, CT).

\section{Thymidine Incorporation Assay}

Bone marrow cells were collected from the tibiae and femurs of wild-type and Rcan $1^{-1-}$ mice. Bone marrow cells were passed through a nylon filter in a single-cell suspension and were resuspended in $100 \mu \mathrm{L}$ sort buffer. Cells were stained with anti-CD34 antibody (Alexa Fluor 647 ) and a cocktail of phycoerythrin (PE)-conjuagted antibodies to lineage markers (CD3, CD4, CD8, B220, Gr-1, and CD19) and Sca-1. Lineage or Sca- $1^{+}$cells were discarded by cell sorting. Remaining cells were further separated into $\mathrm{CD}_{3} 4^{+}$and $\mathrm{CD} 34^{-}$cell populations using a FACSAria fluorescence-activated cell sorting system (BD Biosciences). Cells were resuspended in medium containing $100 \mathrm{ng} / \mathrm{mL} \mathrm{mSCF}$ and $100 \mathrm{ng} / \mathrm{mL}$ FLT3-ligand and seeded in 96-well plates $\left(1.85 \times 10^{5} \mathrm{cells} /\right.$ well). Cells were allowed to recover overnight and were then pulsed with $1 \mu \mathrm{Ci}$ of $\left[{ }^{3} \mathrm{H}\right]$ thymidine for 8 hours. Cells were harvested and incorporation was measured on a Wallac 1409 scintillation $\beta$ counter (Wallac Oy, Turku, Finland). To determine eosinophil proliferation, bone marrow-derived eosinophils $\left(2 \times 10^{5}\right.$ cells/well) from wild-type and Rcan $1^{-1-}$ mice were pulsed with $1 \mu \mathrm{Ci}$ of $\left[{ }^{3} \mathrm{H}\right]$ thymidine for 8 hours in the presence of IL-5 $(50 \mathrm{ng} / \mathrm{mL})$. Thymidine incorporation was then measured.

\section{Statistical Analysis}

Analysis of variance and the paired Student's t-test were used for statistical evaluation of data. $P$ values of $<0.05$ were considered significant. Except as specified, data are expressed as means \pm SEM.

\section{Results}

\section{Near-Complete Blockade of OVA-Induced Airway Eosinophilia in Rcan1-Deficient Mice}

We have found that Rcan 1 negatively regulates IgE-mediated mast cell activation. ${ }^{34}$ This finding prompted us to examine the role of Rcan 1 in allergic asthma by using an OVA-induced asthma model in mice. To determine whether Rcan1 regulates lung inflammation in allergic asthma, Rcan $1^{-/-}$mice and $R$ can $^{1^{+/+}}$mice were sensitized and challenged with OVA. After systemic sensitization to OVA and aerosolized OVA challenges, airway inflammation was examined. Histological analysis revealed that $R \mathrm{Rcan}^{-{ }^{-\prime}}$ mice showed reduced inflammatory cells in the lung, compared with that in wild-type mice (Figure 1). Cells in BALF were obtained for differential cell counts. An OVA-induced increase of inflammatory cells in the BALF was seen in Rcan $1^{+/+}$mice. In contrast, total cell number in BALF was reduced by $53 \%$ in $R$ can $^{-1-}$ mice, relative to OVA-treated $R$ can $1^{+/+}$mice (Figure 2A). Analysis of differential cell counts revealed

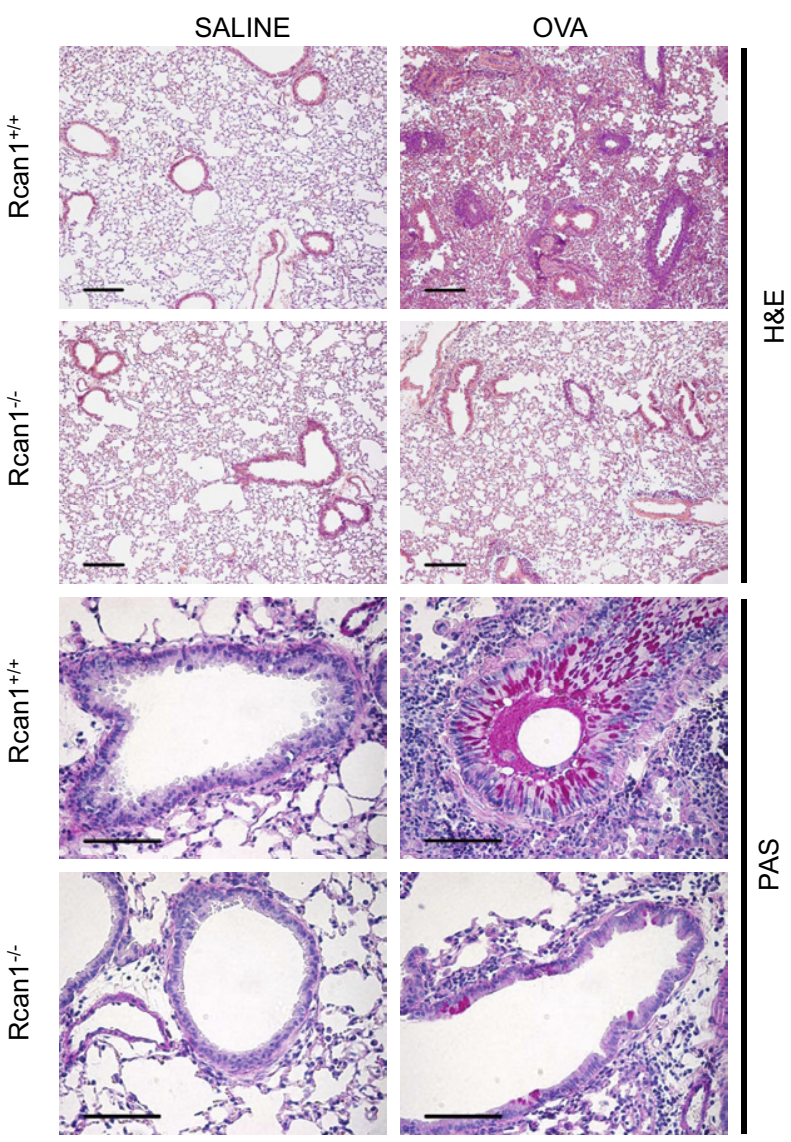

Figure 1. Rcan1 deficiency leads to reduced allergic inflammation in the lung. Rcan $1^{+/+}$and $R \operatorname{can} 1^{-/-}$mice were systemically sensitized with OVA and challenged with aerosolized OVA. Lung and BALF were collected 24 hours after the last OVA challenge. Lung sections from saline or OVAchallenged mice were stained with H\&E or PAS for microscopic examination. Tissue morphology and airway mucus production were similar in both Rcan $1^{+/+}$and $R \operatorname{can} 1^{-/-}$mice under basal conditions. In OVA-challenged mice, H\&E staining revealed a much milder inflammatory cell infiltration in $\operatorname{Rcan~}^{-/-}$mice and PAS staining revealed significantly reduced goblet cell hyperplasia and mucous secretion. Representative images were chosen from 14 mice (in three independent experiments) for OVA-challenged mice and from six mice (in three independent experiments) from saline-treated control mice. Scale bar $=100 \mu \mathrm{m}$

that the number of neutrophils and mononuclear cells was similar in both $R \operatorname{can} 1^{+/+}$and $R c a n 1^{-/-}$mice. Importantly, very little increase of eosinophil numbers could be seen in OVA-challenged Rcan $1^{-\prime-}$ mice (Figure 2A). EPO activity is an eosinophil marker, and the OVA-induced increase of EPO activities in BALF and lung homogenates was dramatically reduced in $R c a n 1^{-1-}$ mice (Figure 2, B and C). MPO is a neutrophil marker, and the OVA-induced levels of MPO activity were similar in both wild-type and Rcan1 $1^{-1-}$ mice (Figure 2E). Thus, Rcan1 deficiency selectively blocked airway eosinophilia.

We also examined Rcan1 expression in the lung of OVA-challenged or saline-treated mice. Rcan1 was constitutively expressed in the lung, as determined by realtime PCR analysis. Of note, the level of Rcan1 was decreased in the lung of OVA-challenged mice (see Supplemental Figure S1, A and B, at http://ajp.amjpathol. org). To examine whether eosinophils express Rcan1, mature eosinophils cultured from wild-type mouse bone marrow cells were used to isolate RNA. To examine 

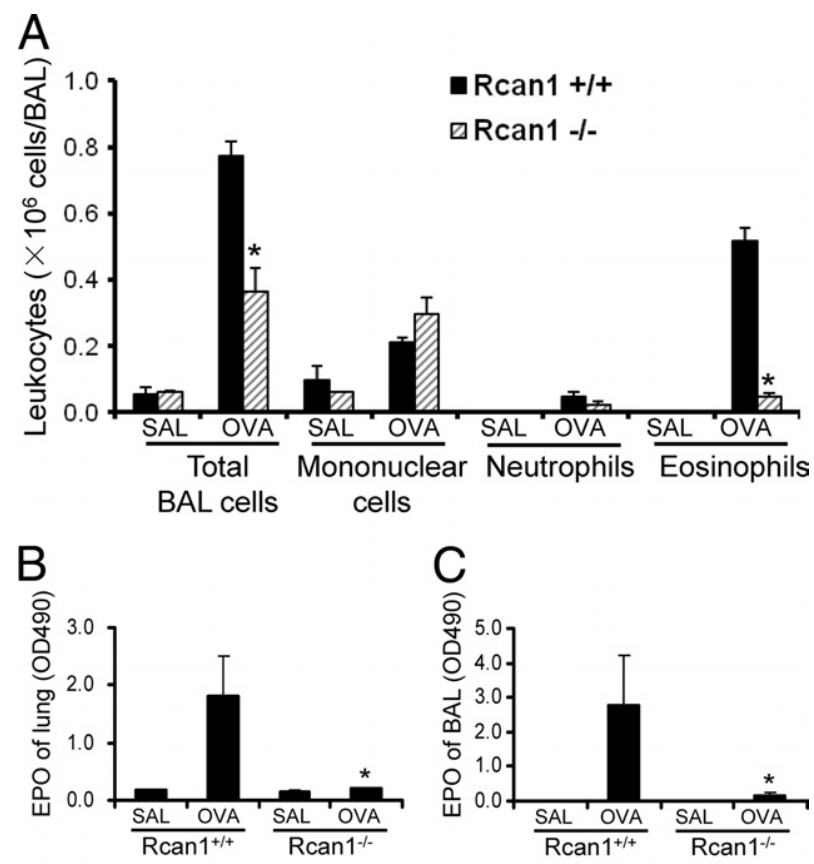

D

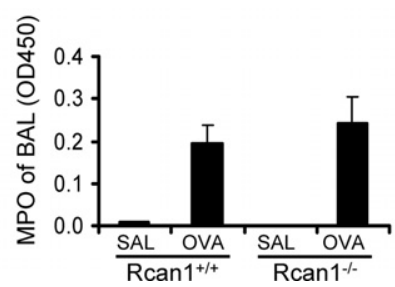

Figure 2. Rcan1 deficiency leads to near-complete absence of eosinophilia in the lung. Rcan $1^{+/+}$and $R \operatorname{can} 1^{-/-}$mice were systemically sensitized with OVA and challenged with aerosolized OVA. Lung and BALF were collected 24 hours after the last OVA challenge. A: Cells in the BALF were obtained for differential cell counts (Diff-Quik staining). Total cell number in the BALF was reduced by $53 \%$ in $R \operatorname{can} 1^{-1-}$ mice, compared with OVA-treated Rcan $1^{+/+}$mice. Importantly, very little increase of eosinophil numbers could be seen in OVA-challenged Rcan1 ${ }^{-/-}$mice. B and C: Lung and BALF were collected for measuring activity of EPO, an eosinophil marker. Little EPO activity could be observed in Rcan $^{-1-}$ mice after OVA challenge. D: Cell pellets in the BALF were also used to determine activity of MPO, a neutrophil marker. No major difference in MPO activity was found between $R c a n 1^{+/+}$ and $R \operatorname{can} 1^{-1-}$ mice ( $n=14$ mice in the OVA group and $n=6$ mice in the saline group, in three independent experiments). ${ }^{*} P<0.05$ versus the OVA-treated Rcan $^{+/+}$group.

whether eosinophil progenitors express Rcan1, bone marrow cells from wild-type mice were stained with antibodies to CD34, Sca-1, and the lineage markers CD3, CD4, CD8, B220, Gr-1, and CD19. CD34 ${ }^{+}$in $^{-}$Sca-1 ${ }^{-}$and CD34- ${ }^{-}$in ${ }^{-}$Sca- $1^{-}$bone marrow cells were obtained by cell sorting and were used for RNA isolation. Mouse bone marrow-derived mast cells after IgE activation were used as a positive control for Rcan1 expression. Rcan1 was found in both eosinophils and eosinophil progenitors (see Supplemental Figure S1C at http://ajp.amjpathol.org).

\section{Rcan1 Deficiency Leads to Reduced Eosinophil Production in Vitro and in Vivo}

Next, we characterized the role of Rcan1 in eosinophil production in vitro and in vivo. Eosinophils originate from the bone marrow and circulate in the blood. To determine whether Rcan 1 regulates the number of eosinophils in the blood, peripheral blood cells from $R \operatorname{can} 1^{-1-}$ and Rcan $1^{+/+}$mice with or without exposure to OVA challenge were stained with antibodies to $\mathrm{IL}-5 \mathrm{R} \alpha$ and Siglec-F and were analyzed by flow cytometry. In naïve animals, peripheral blood eosinophil counts were similar in both Rcan $^{-1-}$ and $R c a n 1^{+/+}$mice (Figure 3, A and B). Systemic sensitization to OVA and aerosolized OVA challenge induced an increase of eosinophils in the blood of Rcan $1^{+/+}$mice. Notably, Rcan $1^{-/-}$mice showed a dramatically impaired response to OVA. Minimal eosinophilia was observed in the blood of Rcan $1^{-1-}$ mice (Figure 3, A and B). Thus, Rcan1 deficiency prevented an OVA-induced increase of eosinophils in the blood, suggesting that eosinophil production was reduced because of Rcan 1 deficiency.

Eosinophil production in vivo is regulated by a specific set of growth factors, including IL-5. ${ }^{37}$ To determine whether growth factor-induced eosinophil production in vivo is regulated by Rcan $1, R c a n 1^{-1-}$ and $R c a n 1^{+/+}$mice were injected with IL-5 intraperitoneally for 6 days. The number of eosinophils in the peripheral blood was examined by differential cell counts for 12 days. Injection of IL-5 induced increased numbers of eosinophils in Rcan $1^{+/+}$mice. By contrast, Rcan $1^{-/-}$mice showed an approximately $50 \%$ reduction in eosinophils, relative to Rcan $1^{+/+}$mice, throughout the time period when IL-5induced eosinophilia was most prominent (day 4 to day 10) (Figure 3, C and D). On day 12, animals were sacrificed, and the blood and bone marrow cells were stained with antibodies to Siglec-F and IL-5R $\alpha$ for flow cytometry analysis. Similarly, Rcan $1^{-1-}$ mice showed fewer eosinophils in the bone marrow, compared with Rcan $1^{+/+}$mice (Figure 3, E and F). Thus, Rcan1 contributed to IL-5induced production of eosinophils in vivo.

In vitro experiments were performed to further evaluate the role of Rcan1 in eosinophil production. Bone marrow cells were cultured under eosinophil-promoting conditions in vitro by using growth medium containing SCF and FLT3-L, followed by IL-5, as described elsewhere, ${ }^{38}$ or by using a conventional colony-forming assay. The same number of bone marrow cells from $R \operatorname{Rcan} 1^{-/-}$and Rcan $1^{+/+}$mice was used for cell culture on day 0 . After culture in growth medium, the yield of mature eosinophils was enumerated on day 14. Rcan $1^{-1-}$ bone marrow cells produced significantly fewer eosinophils, compared with Rcan $1^{+/+}$bone marrow cells (Figure 3G). Similarly, in a colony-forming assay, Rcan $1^{-1-}$ bone marrow cells produced fewer eosinophil colony-forming units, compared with $R$ can $1^{+/+}$bone marrow cells (Figure $3 \mathrm{H}$ ). Eosinophil morphology was examined by light microscopy. No difference could be observed between $R \operatorname{Rcan} 1^{-1-}$ and Rcan $1^{+/+}$eosinophils (data not shown). Thus, Rcan $1^{-/-}$ bone marrow cells produced fewer eosinophils when cultured in vitro.

\section{Reduced Eosinophil Progenitors in Rcan1-Deficient Mice}

Eosinophils originate from progenitor cells in the bone marrow. We reasoned that the potential mechanisms that 
A
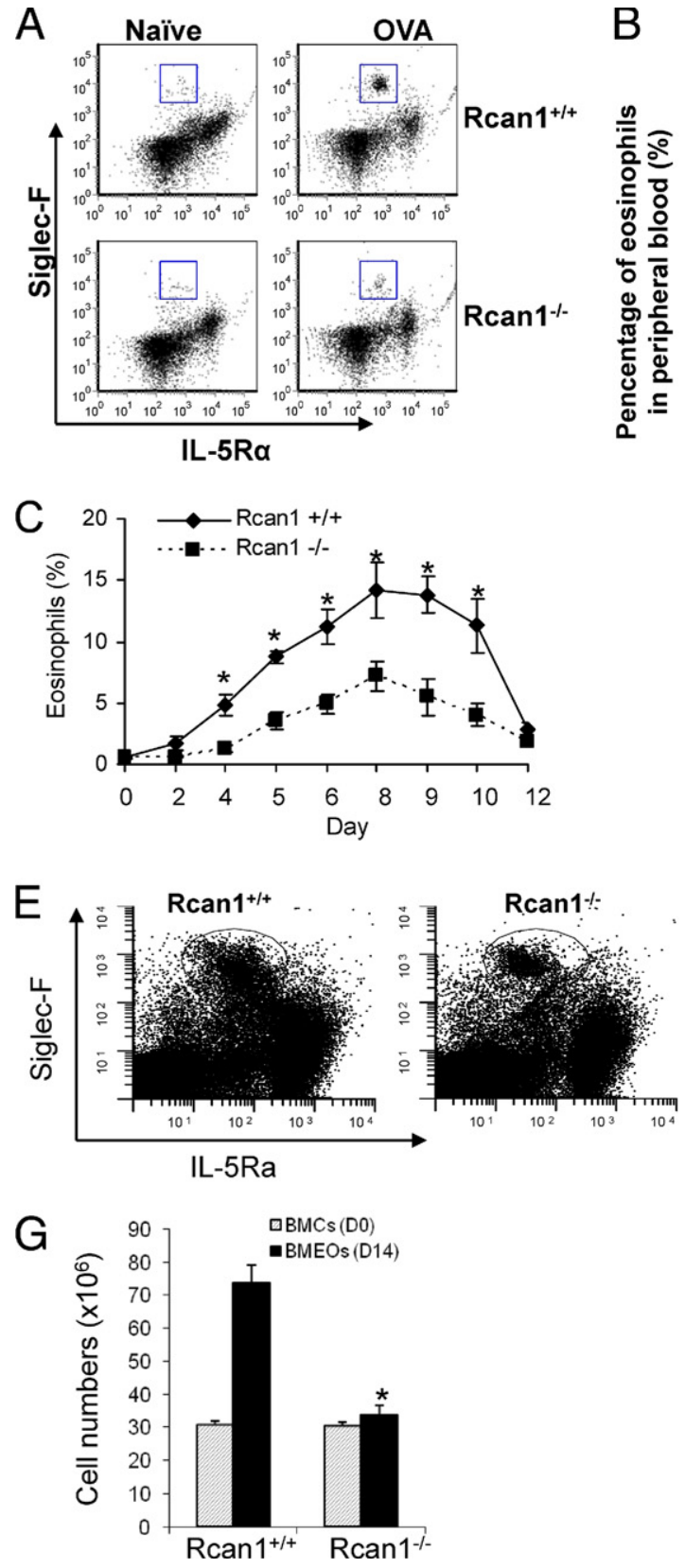

B
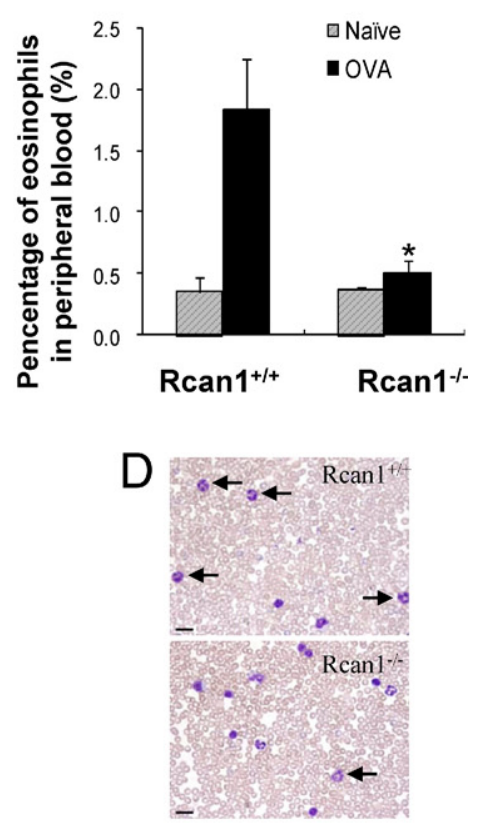

$\mathrm{F}$
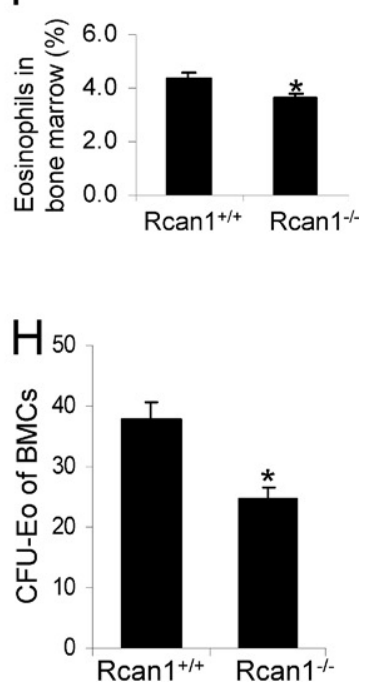

Figure 3. Rcan1 deficiency leads to reduced eosinophil production in vitro and in vivo. $\mathbf{A}$ and $\mathbf{B}$ : Rcan $1^{+/+}$and $R \operatorname{Ran} 1^{-/-}$mice were systemically sensitized with OVA and challenged with aerosolized OVA. Peripheral blood was collected 24 hours after the last OVA challenge. Cells were stained with antibodies to Siglec-F and IL-5R $\alpha$. A: Representative dot plots are shown for Siglec-F ${ }^{+}$and IL-5R $\alpha^{+}$cells (eosinophils) from $R \operatorname{Ran} 1^{+/+}$and $R \operatorname{can} 1^{-/-}$mice. B: Summaries of the percentage of Siglec- $\mathrm{F}^{+}$and IL-5R $\alpha^{+}$cells (eosinophils) are shown. OVA challenge induced increase of eosinophils in $\operatorname{Rcan} 1^{+/+}$ mice but not in $R \operatorname{can} 1^{-1-}$ mice. Data are reported as means \pm SEM $(n=8$ mice in each group from two independent experiments). ${ }^{*} P<0.05$ versus the OVA-treated $R \operatorname{Ran} 1^{+/+}$group. C-F: Recombinant murine IL-5 (10 $\mu \mathrm{g} /$ day, once daily) was injected intraperitoneally into $R \mathrm{can} 1^{+/+}$and $R \mathrm{Can} 1^{-/-}$mice for 6 days (days 0 to 5). Peripheral blood was collected at various time points and examined under Diff-Quik staining. Differential cell counts were performed by examination of blood smears. The percentage of eosinophils was enumerated by counting 200 cells/slide. Data are reported as means \pm SEM ( $n=6$ mice in each group from two independent experiments). C: ${ }^{*} P<0.05$ versus the $R \operatorname{Ran} 1^{->}$ group. Typical appearances of eosinophils (arrows) in blood smears are shown in $\mathbf{D}$ for samples from Rcan $^{+/+}$and Rcan $^{-/-}$mice at day 8 after IL-5 injection. Scale bar $=20 \mu \mathrm{m}$. On day 12 , mice were sacrificed, and bone marrow cells were stained with antibodies to Siglec-F and IL-5R $\alpha$ and analyzed by flow cytometry. E: Siglec-F $\mathrm{F}^{+}$and IL-5R $\alpha^{+}$cells were identified as eosinophils. F: $\operatorname{Rcan} 1^{-1-}$ mice showed reduced number of eosinophils. Data are reported as means \pm SEM ( $n=6$ mice in each group from two independent experiments). ${ }^{*} P<0.05$ versus the Rcan $1^{+/+}$group. G: Bone marrow cells from Rcan $1^{+/+}$and $R \operatorname{can} 1^{-/-}$mice were cultured in medium supplemented with rmSCF, rmFLT3-L and rmIL-5 in vitro for 14 days. The same number of bone marrow cells (BMCs) was used at the beginning of the culture on day 0 (D0). Mature bone marrow-derived eosinophils (BMEOs) were examined on day 14 (D14) under Diff-Quik staining and by flow cytometry. Data obtained by microscopic examination are reported as means \pm SEM from 12 mice in four independent experiments. ${ }^{*} P<0.05$ versus the $R \operatorname{can} 1^{+/+}$D14 group. H: Eosinophil colony-forming assay. Bone marrow cells $\left(9 \times 10^{3}\right.$ cells) were cultured in methylcellulose medium containing $50 \mathrm{ng} / \mathrm{mL}$ of $\mathrm{rmIL}-5$ for 12 days, and the numbers of colonies were counted. Bone marrow cells from Rcan $^{-1-}$ mice produced fewer eosinophil colonies. Data are reported as means \pm SEM of eight independent experiments in triplicate. ${ }^{*} P<$ 0.05 versus the $R \operatorname{can} 1^{+/+}$group. contribute to the reduced eosinophil production in vivo and in vitro may include a reduction in the number of eosinophil progenitors in the bone marrow or impaired developmental capacity of eosinophil progenitors.

Eosinophil progenitors in the bone marrow have recently been identified as $\mathrm{Lin}^{-} \mathrm{Sca}-1^{-} \mathrm{CD} 34^{+} \mathrm{IL}-5 \mathrm{R} \alpha^{+} \mathrm{C}-$ Kit ${ }^{\text {low }}$ cells. ${ }^{10}$ To determine whether Rcan1 regulates eosinophil progenitors, bone marrow cells from Rcan $1^{-1-}$ and $R$ can $1^{+/+}$mice were stained with various antibodies and analyzed by flow cytometry for enumeration of $\mathrm{Lin}^{-}$Sca-1- ${ }^{-} \mathrm{CD} 34^{+} \mathrm{IL}-5 \mathrm{R} \alpha^{+}$C-Kit ${ }^{\text {low }}$ cells, as described elsewhere. ${ }^{10}$ Naïve Rcan $1^{-/-}$mice showed significantly reduced numbers of eosinophil progenitors, compared with $R c a n 1^{+/+}$mice (Figure 4, A-C). Systemic sensitization to OVA and aerosolized OVA challenges induced a strong increase $(116 \%)$ in the number of eosinophil pro- genitors in the bone marrow of wild-type mice. Importantly, OVA-challenged Rcan $1^{-/-}$mice showed severely reduced numbers of eosinophil progenitors, compared with $R c a n 1^{+/+}$mice (Figure 4, A, D, and E). Thus, both naïve and OVA-challenged $R$ can $^{-1-}$ mice demonstrated severely reduced numbers of eosinophil progenitors in the bone marrow.

To determine whether Rcan1 influences the developmental capacity of the eosinophil progenitors, Lin ${ }^{-}$Sca$1^{-} \mathrm{CD} 34^{+} \mathrm{IL}-5 \mathrm{R} \alpha^{+} \mathrm{c}-\mathrm{Kit}{ }^{\text {low }}$ cells were obtained from bone marrow by cell sorting. The same numbers of sorted eosinophil progenitors (400 cells) from Rcan $1^{-/-}$and Rcan $1^{+/+}$mice were used in the cell culture. Notably, similar numbers of eosinophil CFU were observed in both Rcan $1^{-/-}$and Rcan $1^{+/+}$mice after culture for 20 days (Figure 5A). Likewise, eosinophils obtained by culturing 
A

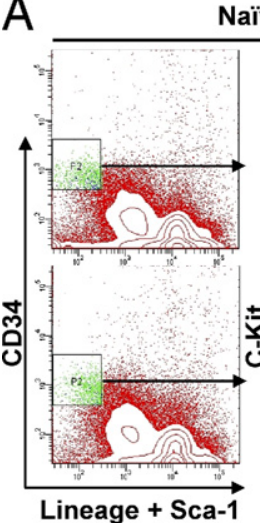

B

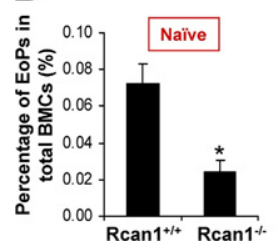

Naïve

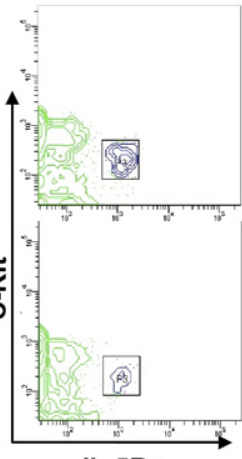

IL-5R $\alpha$

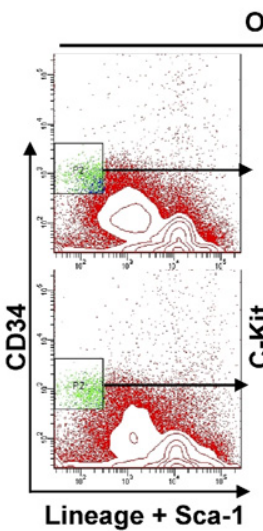

D

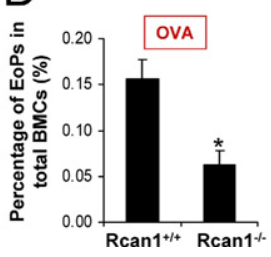

OVA

Rcan1 $^{+/+}$Rcan1 $\%$

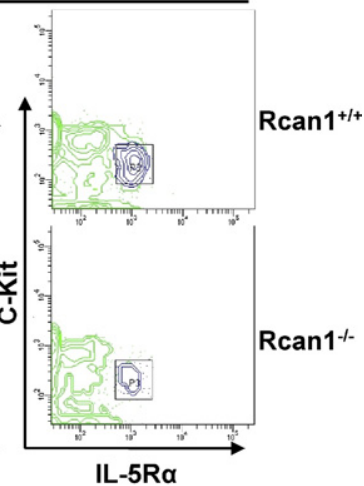

E
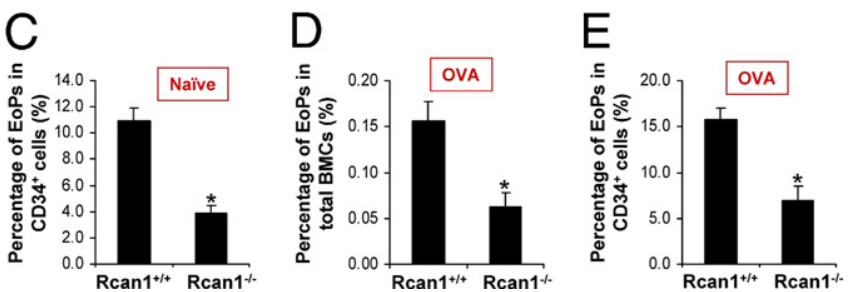

Figure 4. Rcan1 deficiency leads to reduced eosinophil progenitor cell production in vivo. A: Bone marrow cells from Rcan $^{+/+}$and Rcan $1^{-1-}$ mice were stained with antibodies against lineage markers including Sca-1, CD34, IL-5R $\alpha$ chain, and c-Kit. Eosinophil progenitor cells (EoPs) are identified as $\mathrm{Lin}^{-} \mathrm{Sca}-$ $1^{-} \mathrm{CD} 34^{+} \mathrm{IL}-5 \mathrm{R} \alpha^{+} \mathrm{c}-\mathrm{Kit}{ }^{\text {low }}$ cells. Representative flow cytometry profiles are shown. B and C: Summaries of the flow cytometry analysis show that bone marrow cells from naïve Rcan $^{-1}$ mice contain significantly reduced number of EoPs. The percentage of EoPs in total bone marrow cells $(\mathbf{B})$ or in $\mathrm{CD}_{3} 4^{+}$cells $(\mathbf{C})$ is reduced. Data are reported as means $\pm \operatorname{SEM}(n=8$ mice from four independent experiments). $\mathbf{D}$ and $\mathbf{E}$ : Rcan $1^{+/+}$and $R \operatorname{can} 1^{-/-}$mice were systemically sensitized with OVA and challenged with aerosolized OVA (as described in Materials and Methods). Bone marrow cells were analyzed by flow cytometry. OVA challenge increased EoPs in Rcan $^{+/+}$mice. Bone marrow cells from OVA-challenged $R \operatorname{Ran} 1^{-/}$mice contain reduced number of EoPs. The percentage of EoPs in total bone marrow cells (D) or in $\mathrm{CD} 34^{+}$cells (E) is reduced. Data are reported as means \pm SEM ( $n=8$ mice from four independent experiments). ${ }^{*} P<0.05$ versus the $\operatorname{Rcan} 1^{+/+}$group. bone marrow cells from both $R \operatorname{Ran} 1^{-1-}$ and Rcan $1^{+/+}$ mice for 14 days in growth medium showed similar fluorescence intensities for Siglec-F (Figure 5B). No morphological difference could be seen between $R \operatorname{Rcan} 1^{-1-}$ and Rcan $1^{+/+}$eosinophils (Figure $5 \mathrm{C}$ ). Thus, Rcan 1 does not appear to influence the developmental capacity of eosinophils in vitro.

We further examined whether Rcan1 affects the proliferation capacity of eosinophils or eosinophil progenitors. CD34 ${ }^{+} \mathrm{Lin}^{-} \mathrm{Sca}-1^{-}$and CD34- Lin $^{-}$Sca- ${ }^{-}$bone marrow cells were sorted by flow cytometry. These freshly isolated bone marrow cells and bone marrow-derived eosinophils were pulsed with $\left[{ }^{3} \mathrm{H}\right]$ thymidine, and the incorporation of $\left[{ }^{3} \mathrm{H}\right]$ thymidine was determined. No difference in $\left[{ }^{3} \mathrm{H}\right]$ thymidine incorporation was seen between $R \operatorname{can} 1^{-1-}$ and Rcan $1^{+/+} \mathrm{CD}^{+/} 4^{+}$cells or between Rcan $^{-1-}$ and Rcan $1^{+/+}$CD34 ${ }^{-}$cells (Figure 5D). Similarly, no difference in $\left[{ }^{3} \mathrm{H}\right]$ thymidine incorporation was seen between Rcan $1^{-/-}$and $R \operatorname{can} 1^{+/+}$eosinophils (Figure 5E). Thus, Rcan1 does not affect the proliferation of eosinophils or eosinophil progenitors.

\section{Decreased Calcineurin Activity in Rcan $1^{-1-}$ CD34 ${ }^{+}$Bone Marrow Cells}

The function of Rcan1 is largely associated with calcineurin activity; however, little is known about calcineurin in eosinophils. To determine calcineurin expression in eosinophils, bone marrow-derived eosinophils from $R$ can $^{-/-}$and $R \operatorname{can} 1^{+/+}$mice were stimulated with IL-5 or left unstimulated. Cell lysates were analyzed for calcineurin A by Western blot analysis. We found that calcineurin is constitutively expressed in eosinophils. IL-5 stimulation did not change the expression level of calcineurin. No difference in calcineurin expres- sion level was observed between $R \operatorname{can} 1^{-1-}$ and Rcan $1^{+/+}$eosinophils (Figure 6A).

To examine calcineurin expression in eosinophil progenitors, bone marrow cells from $R c a n 1^{-1-}$ and Rcan $1^{+/+}$mice were depleted with lineage markers and Sca-1. CD34 ${ }^{+} \mathrm{Lin}^{-}$Sca-1 ${ }^{-}$and CD34 ${ }^{-} \mathrm{Lin}^{-}$Sca-1 ${ }^{-}$bone marrow cells were obtained by cell sorting. The CD34 ${ }^{+}$ cell population contains eosinophil progenitors. CD34 ${ }^{-}$ cells were also included as controls. These cells were subjected to Western blot analysis for calcineurin A and a calcineurin activity assay. No difference in calcineurin level was observed between CD34 ${ }^{+}$cells from Rcan $^{-/-}$versus Rcan $1^{+/+}$mice or between CD34 ${ }^{-}$ cells from Rcan $^{-1-}$ versus Rcan $1^{+/+}$mice (Figure 6B). Importantly, the calcineurin activity assay revealed that CD34 ${ }^{+}$Lin $^{-}$Sca- $1^{-}$bone marrow cells from Rcan $1^{-1-}$ mice showed a decreased level of calcineurin activity, compared with Rcan $1^{+/+}$mice (Figure 6C).

Eosinophil lineage development is controlled by several classes of transcription factors. Of these transcription factors, GATA-1 is the most important for eosinophil lineage specification. ${ }^{39}$ To examine whether Rcan1 regulates eosinophil production via GATA-1, we determined GATA-1 expression in eosinophil progenitors. Bone marrow cells from $R \operatorname{can} 1^{-/-}$and $R \operatorname{can} 1^{+/+}$mice were depleted with lineage markers and Sca-1. CD34 ${ }^{+} \mathrm{Lin}^{-}$Sca- $1^{-}$and CD34 ${ }^{-} \mathrm{Lin}^{-}$Sca- ${ }^{-}$bone marrow cells were obtained by cell sorting and analyzed by RTPCR for GATA-1 expression. CD $34^{+}$cells from both Rcan $1^{-/-}$and $R$ can $1^{+/+}$mice expressed similar levels of GATA-1. A similar level of GATA-1 was also observed in CD34- cells (see Supplemental Figure S2A at http:// ajp.amjpathol.org). To examine GATA-1 expression at the protein level, CD34 ${ }^{+} \mathrm{Lin}^{-} \mathrm{Sca}-1^{-}$bone marrow cells from Rcan $1^{-/-}$and $R$ can $1^{+/+}$mice were obtained by cell sorting and then were fixed, permeabilized, and stained for 

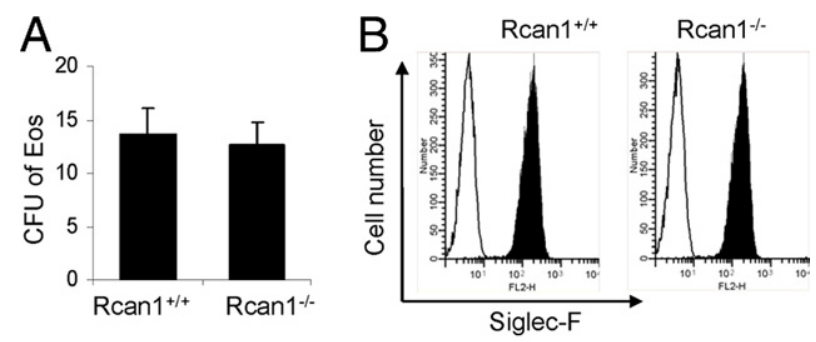

C
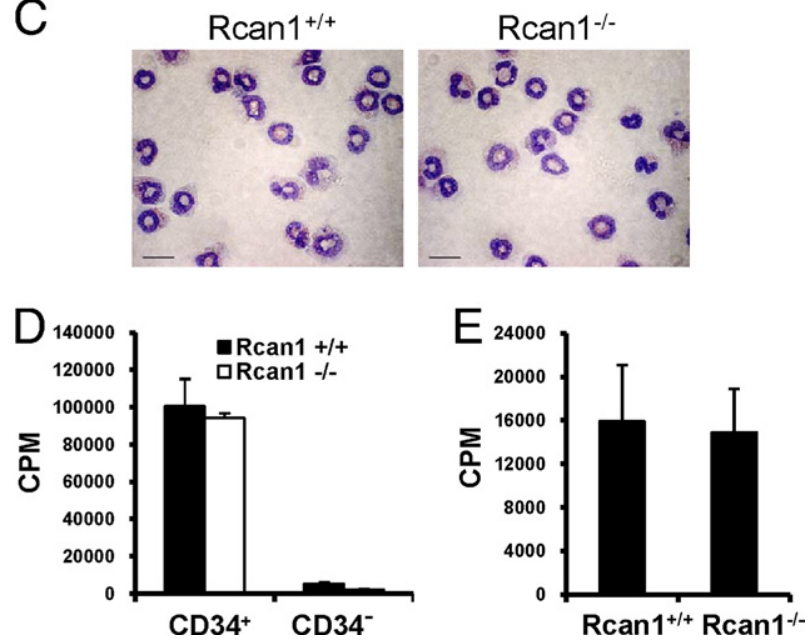

Figure 5. Rcan 1 deficiency does not affect eosinophil maturation in vitro. A Bone marrow cells were stained with various antibodies to identify Lin $^{-}$Sca$1^{-} \mathrm{CD} 34^{+} \mathrm{IL}-5 \mathrm{R} \alpha^{+} \mathrm{c}-\mathrm{Kit}{ }^{\text {low }}$ cells as eosinophil progenitor cells (EoPs). Fluorescence-activated cell-sorted EoPs ( 400 cells) were plated in methylcellulose medium containing $50 \mathrm{ng} / \mathrm{mL}$ of IL-5. After in vitro culture for 20 days, EoPs from both $R \operatorname{Rcan} 1^{+/+}$and $R \operatorname{can} 1^{-/-}$mice produced a similar number of colonies. Data are reported as means \pm SEM of four independent experiments. B: Representative histograms show that in vitro cultured bone marrow-derived eosinophils from both $R \operatorname{Ran} 1^{+/+}$and $R \operatorname{Ran} 1^{-/-}$mice express similar levels of Siglec-F. C: Bone marrow-derived eosinophils cultured in vitro from both Rcan $^{+/+}$and $R \operatorname{Ran} 1^{-/-}$mice show similar morphology under Diff-Quik staining. Scale bar $=20 \mu \mathrm{m}$. D: Bone marrow cells from wild-type and Rcan1 $1^{-1}$ mice were stained with anti-CD34 (Alexa Fluor 647) and a cocktail of antibodies to lineage markers (CD3, CD4, CD8, B220, Gr-1, and $\mathrm{CD} 19)$ and Sca-1 (PE). Lineage ${ }^{+}$or Sca- $1^{+}$cells were discarded by cell sorting. Remaining cells were further separated into CD $34^{+}$and $\mathrm{CD} 34^{-}$cell populations and pulsed with $\left[{ }^{3} \mathrm{H}\right]$ thymidine for 8 hours. Incorporation was measured on a Wallac $\beta$ counter. Data are reported as means \pm SEM from three independent experiments in triplicate. E: To determine eosinophil proliferation, bone marrow-derived eosinophils from wild-type and Rcan $1^{-/}$mice were pulsed with $\left[{ }^{3} \mathrm{H}\right]$ thymidine for 8 hours in the presence of IL-5, and thymidine incorporation was then measured. Data are reported as means \pm SEM from four independent experiments in triplicate.

GATA-1, c-Kit, and IL-5R $\alpha$ by multicolor staining. A distinct population of IL-5R $\alpha^{+}$C-Kitlow cells was identified as eosinophil progenitors. We found that eosinophil progenitors from both $R \mathrm{Can} 1^{-/-}$and $R \mathrm{can} 1^{+/+}$mice expressed similar levels of GATA-1 (see Supplemental Figure S2, $\mathrm{B}$ and $\mathrm{C}$, at http://ajp.amjpathol.org). Thus, GATA-1 expression in eosinophil progenitors is not affected by Rcan1 deficiency.

\section{Effects of Rcan1 on Eosinophil Migration and IL-4 Production, but Not Apoptosis}

After entering the circulation, eosinophils are recruited into inflammatory sites. Eotaxins play an important role in eosinophil recruitment into the lung. ${ }^{40}$ To determine whether Rcan1 regulates eosinophil trafficking, bone marrow-derived Rcan $1^{-1-}$ and Rcan $1^{+/+}$eosinophils were subjected to a chemotaxis assay in a Transwell plate using eotaxin (CCL11) as a chemoattractant. Rcan $1^{-1-}$ eosinophils showed modestly reduced migration toward eotaxin (Figure 7A). This reduced migration capacity of $R$ can $1^{-1-}$ eosinophils may contribute to reduced eosinophilia in the lung in vivo, as seen in OVAtreated $R \operatorname{Rcan} 1^{-1-}$ mice.

Eosinophils express various adhesion molecules on their surface, including $\alpha 4$ integrin. ${ }^{41}$ To determine whether Rcan 1 deficiency leads to abnormal $\alpha 4$ integrin expression, the $\alpha 4$ integrin level on eosinophils was examined by flow cytometry. Bone marrow-derived eosinophils from both $R$ can $^{-/-}$and $R c a n 1^{+/+}$mice expressed similar levels of $\alpha 4$ integrin (Figure 7B). Stimulation of eosinophils with eotaxin for 1 hour induced an increase of $\alpha 4$ integrin expression. Eotaxin-induced increase of $\alpha 4$ integrin expression was similar in both $R \operatorname{can} 1^{-1-}$ and Rcan $1^{+/+}$eosinophils (Figure 7B), suggesting that Rcan 1 deficiency does not affect the expression of the adhesion molecule $\alpha 4$ integrin.

To examine whether Rcan1 regulates eosinophil signal transduction, bone marrow-derived eosinophils were

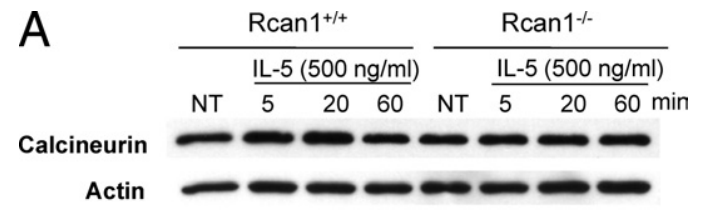

B

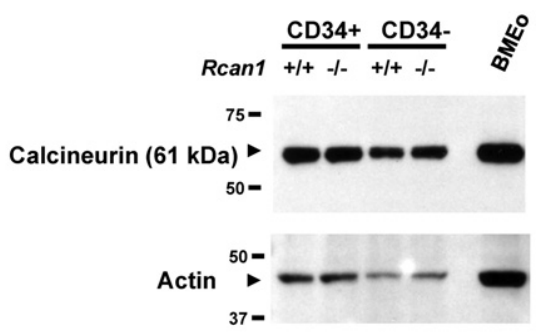

C

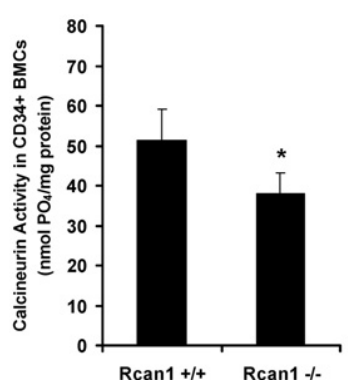

Figure 6. Effects of Rcan 1 on calcineurin expression or activity in eosinophils and their progenitors. A: Eosinophils cultured from the bone marrow of Rcan $1^{+/+}$and $R \operatorname{Ran} 1^{-/-}$mice were treated with IL-5 $(500 \mathrm{ng} / \mathrm{mL})$ for 5,20 , or 60 minutes or left untreated (NT). Cell lysates were analyzed by Western blotting for calcineurin. B: CD $34^{+} \mathrm{Lin}^{-} \mathrm{Sca}-1^{-}$and $\mathrm{CD} 34^{-} \mathrm{Lin}^{-} \mathrm{Sca}-1^{-}$bone marrow cells were obtained by cell sorting (see Materials and Methods). Eosinophils cultured from the bone marrow of wild-type mice (BMEo) were included as a control. Cell lysates were probed for calcineurin and actin. C: $\mathrm{CD} 34^{+} \mathrm{Lin}^{-} \mathrm{Sca}-1^{-}$and $\mathrm{CD} 34^{-} \mathrm{Lin}^{-} \mathrm{Sca}-1^{-}$bone marrow cells were obtained by cell sorting and subjected to a calcineurin activity assay. Data are reported as means \pm SEM ( $n=8$ mice in three independent experiments). ${ }^{*} P<0.05$ versus the $R \operatorname{can} 1^{+/+}$group. 
A

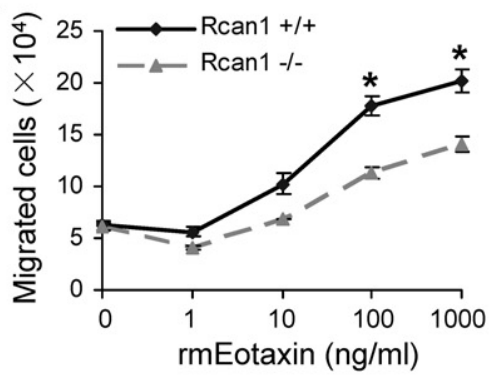

B
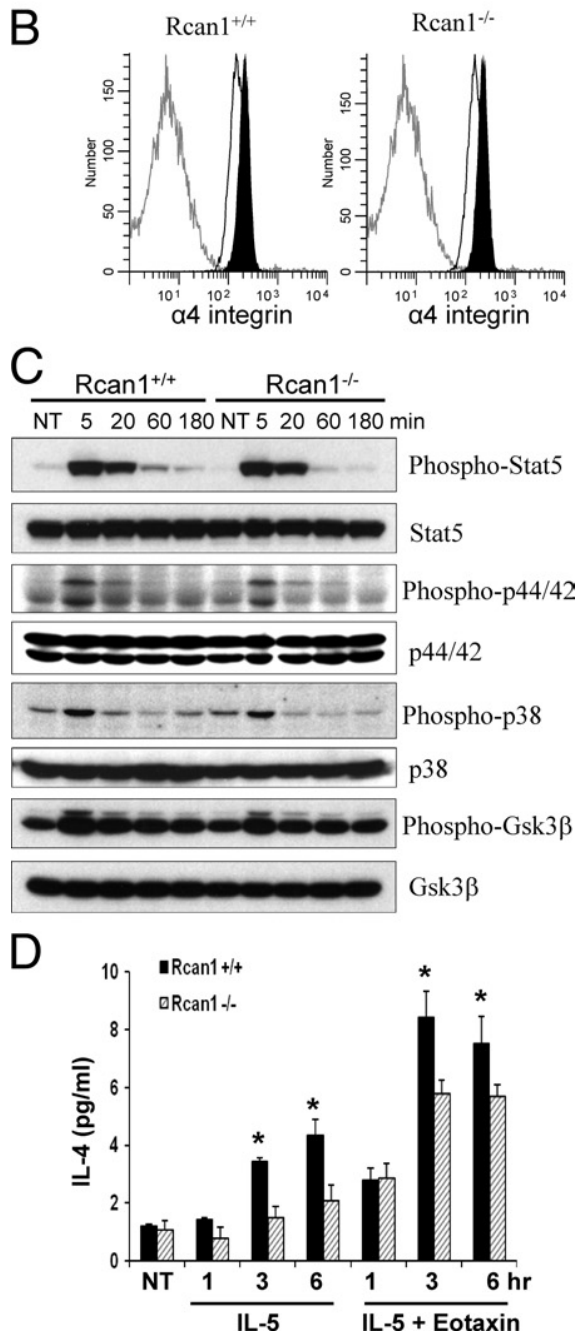

Figure 7. Effects of Rcan1 deficiency on eosinophil migration and function. A: The migration capacity of bone marrow-derived eosinophils from $\mathrm{Rcan1}^{+/+}$and Rcan $1^{-/}$mice was examined using a Transwell assay. Eotaxin (CCL11, 1 to 1000 $\mathrm{ng} / \mathrm{mL}$ ) was used as a chemoattractant. Eosinophils from Rcan1 $1^{-1-}$ mice show decreased migration capacity. Data are reported as means \pm SEM of three independent experiments. ${ }^{*} P<0.05$ versus the $R c a n 1^{-1-}$ group. B: Eosinophils from $\operatorname{Rcan~}^{+/+}$and $\operatorname{Rcan}^{-/-}$mice were treated with eotaxin $(100 \mathrm{ng} / \mathrm{mL})$ for 1 hour. Expression of $\alpha 4$ integrin was analyzed by flow cytometry. Gray open profile, isotype antibody; black open profile, no-treatment group; black solid profile, eotaxin-treated group. Similar levels of eotaxin-induced $\alpha 4$ integrin expression were seen in both $\operatorname{Rcan}^{+/+}$and Rcan1 ${ }^{-/-}$eosinophils. C: Bone marrow-derived eosinophils from Rcan $^{+/+}$and $R c a n 1^{-/-}$mice were stimulated with IL-5 (500 ng/ $\mathrm{mL}$ ) for various lengths of time. Total cell lysates were prepared for Western blotting. A similar pattern of IL-5 induced phosphorylation is seen in both $\operatorname{Rcan1}^{+/+}$and Rcan $1^{-/-}$eosinophils. D: Rcan1 deficiency leads to impaired IL-4 production. Eosinophils from Rcan $^{+/+}$and $R \operatorname{Ran} 1^{-/}$mice were stimulated with IL-5 (500 $\mathrm{ng} / \mathrm{mL})$ or with IL-5 and eotaxin $(100 \mathrm{ng} / \mathrm{mL})$ for various lengths of time. Untreated cells (NT) served as control. Cell-free supernatants were collected for the detection of IL- 4 by enzyme-linked immunosorbent assay. Error bars indicate standard error from six independent experiments. ${ }^{*} P<0.05$ versus the $R$ can $1^{-/-}$group. treated with IL-5. Phosphorylation of various signaling molecules was examined. No major difference in phosphorylation patterns of Stat5, MAP kinase p44/42, p38, and Gsk3 $\beta$ was observed between $R$ can $^{-1-}$ and Rcan $1^{+/+}$eosinophils (Figure 7C).

We reasoned that eosinophil survival might also affect eosinophilia in the lung. Others have shown that Rcan1 regulates CD4 T-cell apoptosis. ${ }^{30}$ We attempted to determine whether Rcan1 regulates eosinophil apoptosis. Mature eosinophils were obtained by culturing bone marrow cells from Rcan $1^{+/+}$and Rcan $1^{-/-}$mice. After eosinophil maturation, IL-5 was withdrawn from the culture medium to induce apoptosis. Apoptotic cells were monitored for 1,2 , and 3 days by using annexin $V$ and propidium iodide staining. Withdrawal of IL-5 induced a similar number of apoptotic cells in both $R \operatorname{Rcan} 1^{+/+}$and Rcan $1^{-/-}$eosinophils (data not shown). Thus, Rcan1 appears to have no effect on eosinophil apoptosis. In addition, the baseline level of eosinophils in the intestine was examined. Both Rcan $1^{+/+}$and $R \operatorname{can} 1^{-/-}$mice appear to have similar levels of eosinophils in the intestine (see Supplemental Figure S3 at http://ajp.amjpathol.org).

In local tissues, eosinophils produce inflammatory mediators, such as IL-4, that contribute to airway inflammation. To examine whether Rcan 1 regulates production of cytokines and chemokines, eosinophils from Rcan ${ }^{-1-}$ and $R \operatorname{can} 1^{+/+}$mice were stimulated with IL-5 or with IL-5 and eotaxin. Cell-free supernatants were harvested to examine cytokines and chemokines using a cytokine multiplex assay that detects 23 cytokines and chemokines. The majority of the tested cytokines and chemokines were undetectable. Of note, IL-4 was the only cytokine found to be reduced in Rcan $1^{-1-}$ eosinophils after stimulation with IL-5 or with IL-5 and eotaxin (Figure 7D). No major differences of IL-9, IL-13, interferon $\gamma(\mathrm{IFN} \gamma)$, and granulocyte-macrophage colony-stimulating factor (GMCSF) production were observed between Rcan $^{-/-}$and Rcan $1^{+/+}$eosinophils (see Supplemental Figure S4 at http://ajp.amjpathol.org). These findings suggest that Rcan1 deficiency does not lead to overall eosinophil functional deficiency but rather that Rcan1 selectively affects eosinophil migration and IL-4 production.

\section{Discussion}

Asthma is associated with marked infiltration of eosinophils in the lung. Knowledge of the essential role of eosinophils in allergic asthma seen in eosinophil-deficient mice $^{7,8}$ and in humans ${ }^{2-4}$ has led to the concept of targeting eosinophils as a therapeutic approach for the treatment of asthma. However, clinical trials using antiIL-5 antibodies to target eosinophils failed to eliminate tissue eosinophils and did not improve clinical symptoms in patients with asthma. ${ }^{42,43}$ These findings highlight the importance of eosinophils in asthma and an urgent need for identifying mechanisms that control lung eosinophilia in allergic asthma.

In the present study, we identified Rcan1 as a novel signaling molecule essential for allergen-induced eosinophilia. Notably, Rcan $1^{-1-}$ mice showed a near-complete 
absence of eosinophilia in the BALF, lung, and blood in OVA-challenged mice. Further analysis revealed that Rcan $1^{-1-}$ mice possess reduced numbers of eosinophil progenitor cells in the bone marrow. Eosinophil progenitor cells provide a constant supply of mature eosinophils in the blood and tissues. The number of eosinophil progenitors is known to be increased in allergic asthma. ${ }^{9-13}$ We found that allergen challenge induces a significant increase of eosinophil progenitors in wild-type mice, but not in $R \mathrm{Ran}^{-1-}$ mice. Thus, the reduced number of eosinophil progenitor cells likely contributes to the lack of eosinophilia in OVA-challenged Rcan $1^{-1-}$ mice. Accordingly, Rcan1 represents a new target in the control of the eosinophil population in allergic asthma.

The near-complete absence of eosinophilia in Rcan $1^{-1-}$ mice prompted us to determine various functional and developmental features of eosinophils, including maturation, migration, signal transduction, and cytokine production. In vivo, IL-5 induced fewer eosinophils in the blood in Rcan $1^{-/-}$mice, compared with Rcan $1^{+/+}$ mice; in vitro, bone marrow cells from Rcan $1^{-1-}$ mice produced fewer eosinophils by cell culture. These reduced eosinophil numbers in vivo and in vitro are likely due to reduced numbers of eosinophil progenitor cells in the bone marrow. This contention is based on our observation that the same number of eosinophil progenitor cells obtained by cell sorting from both $R \mathrm{Rcan}^{-1-}$ and Rcan $1^{+/+}$mice resulted in a similar number of eosinophil colonies in cell culture. Eosinophil progenitor cells isolated from Rcan $1^{-1-}$ mice appear to develop normally into mature eosinophils with normal morphology and Siglec-F expression. This finding suggests that mechanisms governing eosinophil maturation are distinct from eosinophil progenitor regulation. This notion is consistent with other reports that the dbIGATA enhancer is not essential for eosinophil differentiation ex vivo, ${ }^{37}$ but is critical for the generation of eosinophil progenitors. ${ }^{38}$

We observed that the decrease in the number of eosinophils in the BALF of OVA-treated Rcan $1^{-1-}$ mice is more dramatic than the decrease in the number of eosinophil progenitors in Rcan $1^{-/-}$mice. Of note, in Rcan $1^{-/-}$ mice eosinophils showed reduced migration capacity in response to the chemoattractant eotaxin. Thus, it is likely that the decreased numbers of eosinophil progenitors, together with the impaired eosinophil migration capacity, collectively contribute to the severe deficiency of eosinophilia in Rcan1 ${ }^{-1-}$ mice.

Eosinophils contribute to lung inflammation by producing inflammatory mediators such as IL-4. We found that Rcan $1^{-1}$ eosinophils produced less IL-4 in response to stimulation with IL-5 or with IL-5 and eotaxin. Accordingly, Rcan 1 likely regulates allergic inflammation by reducing the number of eosinophils and their mediator production capability.

It is noteworthy that eosinophils developed from both Rcan $1^{-/-}$and Rcan $1^{+/+}$mice showed a similar pattern of phosphorylation of various signaling molecules, including Stat5, p38, p44/42 MAP kinase, and Gsk3 $\beta$, in response to IL-5 stimulation. Likewise, eosinophils from both Rcan $1^{-/-}$ and Rcan $1^{+/+}$mice showed similar levels of $\alpha 4$ integrin expression. These finding suggest that Rcan 1 deficiency does not generate an overall functional deficiency on eosinophils. Rather, Rcan1 modulates specific aspects of eosinophil function, including migration and IL-4 production.

The positive regulatory role of Rcan 1 in eosinophil progenitors and eosinophilia development in allergic lung inflammation seen in the present study is in contrast to the negative effects of Rcan1 in mast cells. ${ }^{34}$ Rcan 1 deficiency leads to enhanced calcineurin activity, increased NF $\kappa$ B and NFAT activation, and increased cytokine production by mast cells in vitro. ${ }^{34}$ In the present study, Rcan1 deficiency led to reduced calcineurin activity in eosinophil progenitors. The contrasting effects of Rcan1 on mast cells and eosinophil progenitors suggest that Rcan 1 has distinct effects on specific cell types or tissues. The opposite effects of Rcan1 on calcineurin activity have been reported previously. Rcan 1 can function as an inhibitor ${ }^{29,30}$ or a facilitator ${ }^{24,28,31-33}$ of calcineurin. The exact mechanisms of such opposite effects are unclear. One possibility is that Rcan 1 is associated and regulated by different molecules in different cell types. Rcan 1 has been found to be physically associated with various molecules, including TAK $1,{ }^{44} \mathrm{TAB} 2,{ }^{44} \mathrm{GSK}$ $3 \beta,{ }^{45}$ Raf $1,{ }^{46}$ and calcineurin. TAK 1 is able to convert Rcan1 from an inhibitor to a facilitator of calcineurin signaling by direct phosphorylation of Rcan $1 .{ }^{44}$ Similarly, GSK- $3 \beta$ is able to regulate Rcan 1 function. ${ }^{45,47}$ Mehta et $a l^{47}$ showed that the GSK-3 $\beta$ phosphorylation site on Rcan 1 is required for its activating effects on calcineurin but not for its inhibitory effects on calcineurin, and suggested that the inhibitory role of Rcan 1 is likely through competing with other substrates for docking onto calcineurin. To date, there is no report on the role of TAK 1 in eosinophils and their progenitors or in mast cells, and only limited information on the role of GSK- $3 \beta$ in eosinophils and mast cells. There is a possibility that the molecules associated with Rcan 1 such as TAK 1 and GSK- $3 \beta$ may contribute to the distinct role of Rcan 1 in functional regulation of eosinophil progenitors and mast cells.

Our findings, together with those of others, suggest that information generated from one cell type regarding Rcan1 function cannot be readily generalized to other cell types. This notion may be particularly important, considering that Rcan1 has been found in various tissues and cells ${ }^{22,25,26}$ and that studies on Rcan 1 have been performed in various different experimental models, including yeast. ${ }^{48,49}$

In conclusion, we have identified novel roles for Rcan1 in an important regulatory mechanism of eosinophilia in allergic asthma. Rcan1 deficiency leads to reduced production of eosinophil progenitor cells, impaired eosinophil migration capacity, and reduced eosinophilia in the lung. Thus, Rcan1 may serve as a potential target for the treatment of allergic asthma.

\section{References}

1. Arbes SJ Jr, Gergen PJ, Elliott L, Zeldin DC: Prevalences of positive skin test responses to 10 common allergens in the US population: results from the third National Health and Nutrition Examination Survey. J Allergy Clin Immunol 2005, 116:377-383

2. Rothenberg ME, Hogan SP: The eosinophil. Annu Rev Immunol 2006 , $24: 147-174$ 
3. Bousquet J, Chanez P, Lacoste JY, Barnéon G, Ghavanian N, Enander I, Venge P, Ahlstedt S, Simony-Lafontaine J, Godard P, Miche FB: Eosinophilic inflammation in asthma. N Engl J Med 1990, 323: 1033-1039

4. Busse WW, Calhoun WF, Sedgwick JD: Mechanism of airway inflammation in asthma. Am Rev Respir Dis 1993, 147:S20-S24

5. Justice JP, Borchers MT, Crosby JR, Hines EM, Shen HH, Ochkur SI, McGarry MP, Lee NA, Lee JJ: Ablation of eosinophils leads to a reduction of allergen-induced pulmonary pathology. Am J Physiol Lung Cell Mol Physiol 2003, 284:L169-L178

6. Shen HH, Ochkur SI, McGarry MP, Crosby JR, Hines EM, Borchers MT, Wang H, Biechelle TL, O'Neill KR, Ansay TL, Colbert DC, Cormier SA, Justice JP, Lee NA, Lee JJ: A causative relationship exists between eosinophils and the development of allergic pulmonary pathologies in the mouse. J Immunol 2003, 170:3296-3305

7. Lee JJ, Dimina D, Macias MP, Ochkur SI, McGarry MP, O'Neill KR, Protheroe C, Pero R, Nguyen T, Cormier SA, Lenkiewicz E, Colbert D, Rinaldi L, Ackerman SJ, Irvin CG, Lee NA: Defining a link with asthma in mice congenitally deficient in eosinophils. Science 2004, 305: 1773-1776

8. Humbles AA, Lloyd CM, McMillan SJ, Friend DS, Xanthou G, McKenna EE, Ghiran S, Gerard NP, Yu C, Orkin SH, Gerard C: A critical role for eosinophils in allergic airways remodeling. Science 2004, 305:1776-1779

9. Allakhverdi Z, Comeau MR, Smith DE, Toy D, Endam LM, Desrosiers M, Liu YJ, Howie KJ, Denburg JA, Gauvreau GM, Delespesse G: CD34+ hemopoietic progenitor cells are potent effectors of allergic inflammation. J Allergy Clin Immunol 2009, 123:472-478

10. Denburg JA, Keith PK: Eosinophil progenitors in airway diseases: clinical implications. Chest 2008, 134:1037-1043

11. Gauvreau GM, Ellis AK, Denburg JA: Haemopoietic processes in allergic disease: eosinophil/basophil development. Clin Exp Allergy 2009, 39:1297-1306

12. Rådinger M, Lötvall J: Eosinophil progenitors in allergy and asthma—do they matter? Pharmacol Ther 2009, 121:174-184

13. Southam DS, Widmer N, Ellis R, Hirota JA, Inman MD, Sehmi R: Increased eosinophil-lineage committed progenitors in the lung of allergen-challenged mice. J Allergy Clin Immunol 2005, 115:95-102

14. Goldacre MJ, Wotton CJ, Seagroatt V, Yeates D: Cancers and immune related diseases associated with Down's syndrome: a record linkage study. Arch Dis Child 2004, 89:1014-1017

15. Schieve LA, Boulet SL, Boyle C, Rasmussen SA, Schendel D: Health of children 3 to 17 years of age with Down syndrome in the 1997 2005 national health interview survey. Pediatrics 2009, 123:e253e260

16. Forni GL, Rasore-Quartino A, Acutis MS, Strigini P: Incidence of bronchial asthma in Down syndrome. J Pediatr 1990, 116:487-488

17. Kusanagi $\mathrm{Y}$, Ochi $\mathrm{H}$, Matsubara K, Ito M: Hypereosinophilic syndrome in a trisomy 21 fetus. Obstet Gynecol 1998, 92:701-702

18. Shenoy RD, Bhat KG, Kamath N, Kumble Y: Transient myeloproliferative disorder and eosinophilic pericardial effusion in a Down syndrome neonate. Pediatr Hematol Oncol 2008, 25:123-129

19. Christiansen M, Oxvig C, Wagner JM, Qin QP, Nguyen TH, Overgaard MT, Larsen SO, Sottrup-Jensen L, Gleich GJ, Norgaard-Pedersen B: The proform of eosinophil major basic protein: a new materna serum marker for Down syndrome. Prenat Diagn 1999, 19:905-910

20. Fuentes JJ, Pritchard MA, Planas AM, Bosch A, Ferrer I, Estivill X: A new human gene from the Down syndrome critical region encodes a proline-rich protein highly expressed in fetal brain and heart. Hum Mol Genet 1995, 4:1935-1944

21. Crawford DR, Leahy KP, Abramova N, Lan L, Wang Y, Davies KJ: Hamster adapt78 mRNA is a Down syndrome critical region homologue that is inducible by oxidative stress. Arch Biochem Biophys 1997, 342:6-12

22. Rothermel B, Vega RB, Yang J, Wu H, Bassel-Duby R, Williams RS: A protein encoded within the Down syndrome critical region is enriched in striated muscles and inhibits calcineurin signaling. J Biol Chem 2000, 275:8719-8725

23. Fuentes JJ, Genescà L, Kingsbury TJ, Cunningham KW, Pérez-Riba $M$, Estivill X, de la Luna S: DSCR1, overexpressed in Down syndrome, is an inhibitor of calcineurin-mediated signaling pathways. Hum Mol Genet 2000, 9:1681-1690

24. Gorlach J, Fox DS, Cutler NS, Cox GM, Perfect JR, Heitman J: Identification and characterization of a highly conserved calcineurin binding protein, CBP1/calcipressin, in Cryptococcus neoformans. EMBO J 2000, 19:3618-3629

25. Porta S, Martí E, de la Luna S, Arbonés ML: Differential expression of members of the RCAN family of calcineurin regulators suggests selective functions for these proteins in the brain. Eur $\mathrm{J}$ Neurosci 2007, 26:1213-1226

26. Fuentes JJ, Pritchard MA, Estivill X: Genomic organization, alternative splicing, and expression patterns of the DSCR1 (Down syndrome candidate region 1) gene. Genomics 1997, 44:358-361

27. Davies KJ, Ermak G, Rothermel BA, Pritchard M, Heitman J, Ahnn J, Henrique-Silva F, Crawford D, Canaider S, Strippoli P, Carinci P, Min KT, Fox DS, Cunningham KW, Bassel-Duby R, Olson EN, Zhang Z, Williams RS, Gerber HP, Pérez-Riba M, Seo H, Cao X, Klee CB, Redondo JM, Maltais LJ, Bruford EA, Povey S, Molkentin JD, McKeon FD, Duh EJ, Crabtree GR, Cyert MS, de la Luna S, Estivill X: Renaming the DSCR1/Adapt78 gene family as RCAN: regulators of calcineurin. FASEB J 2007, 21:3023-3028

28. Sanna B, Brandt EB, Kaiser RA, Pfluger P, Witt SA, Kimball TR, van Rooij E, De Windt LJ, Rothenberg ME, Tschop MH, Benoit SC, Molkentin JD: Modulatory calcineurin-interacting proteins 1 and 2 function as calcineurin facilitators in vivo. Proc Natl Acad Sci USA 2006, 103:7327-7332

29. Chan B, Greenan G, McKeon F, Ellenberger T: Identification of a peptide fragment of DSCR1 that competitively inhibits calcineurin activity in vitro and in vivo. Proc Natl Acad Sci USA 2005, 102:13075-13080

30. Ryeom S, Greenwald RJ, Sharpe AH, McKeon F: The threshold pattern of calcineurin-dependent gene expression is altered by loss of the endogenous inhibitor calcipressin. Nat Immunol 2003 , $4: 874-881$

31. Vega RB, Rothermel BA, Weinheimer CJ, Kovacs A, Naseem RH, Bassel-Duby R, Williams RS, Olson EN: Dual roles of modulatory calcineurin-interacting protein 1 in cardiac hypertrophy. Proc Natl Acad Sci USA 2003, 100:669-674

32. Kingsbury TJ, Cunningham KW: A conserved family of calcineurin regulators. Genes Dev 2000, 14:1595-1604

33. Hilioti Z, Gallagher DA, Low-Nam ST, Ramaswamy P, Gajer P, Kingsbury TJ, Birchwood CJ, Levchenko A, Cunningham KW: GSK-3 kinases enhance calcineurin signaling by phosphorylation of RCNs. Genes Dev 2004, 18:35-47

34. Yang YJ, Chen W, Edgar A, Li B, Molkentin JD, Berman JN, Lin TJ: Rcan1 negatively regulates $F_{C}$ epsilonRI-mediated signaling and mast cell function. J Exp Med 2009, 206:195-207

35. Iwasaki H, Mizuno S, Mayfield R, Shigematsu $H$, Arinobu $Y$, Seed B, Gurish MF, Takatsu K, Akashi K: Identification of eosinophil lineagecommitted progenitors in the murine bone marrow. J Exp Med 2005 201:1891-1897

36. Dyer KD, Moser JM, Czapiga M, Siegel SJ, Percopo CM, Rosenberg HF: Functionally competent eosinophils differentiated ex vivo in high purity from normal mouse bone marrow. J Immunol 2008, 181:4004-4009

37. Dyer KD, Czapiga M, Foster B, Foster PS, Kang EM, Lappas CM, Moser JM, Naumann N, Percopo CM, Siegel SJ, Swartz JM, Ting-De Ravin S, Rosenberg HF: Eosinophils from lineage-ablated Delta dbIGATA bone marrow progenitors: the dbIGATA enhancer in the promoter of GATA-1 is not essential for differentiation ex vivo. J Immunol 2007, 179:1693-1699

38. Yu C, Cantor AB, Yang H, Browne C, Wells RA, Fujiwara Y, Orkin SH: Targeted deletion of a high-affinity GATA-binding site in the GATA-1 promoter leads to selective loss of the eosinophil lineage in vivo. J Exp Med 2002, 195:1387-1395

39. Hirasawa R, Shimizu R, Takahashi S, Osawa M, Takayanagi S, Kato Y, Onodera M, Minegishi N, Yamamoto M, Fukao K, Taniguchi H, Nakauchi $\mathrm{H}$, Iwama A: Essential and instructive roles of GATA factors in eosinophil development. J Exp Med 2002, 195:1379-1386

40. Zimmermann N, Hershey GK, Foster PS, Rothenberg ME: Chemokines in asthma: cooperative interaction between chemokines and IL-13. J Allergy Clin Immunol 2003, 111:227-242; quiz 243

41. Bochner BS, Schleimer RP: The role of adhesion molecules in human eosinophil and basophil recruitment. J Allergy Clin Immunol 1994 94:427-438; quiz 439

42. Leckie MJ, ten Brinke A, Khan J, Diamant Z, O'Connor BJ, Walls CM, Mathur AK, Cowley HC, Chung KF, Djukanovic R, Hansel TT, Holgate ST, Sterk PJ, Barnes PJ: Effects of an interleukin-5 blocking monoclonal antibody on eosinophils, airway hyper-responsiveness, and the late asthmatic response. Lancet 2000, 356:2144-2148 
43. Kips JC, O'Connor BJ, Langley SJ, Woodcock A, Kerstjens HA, Postma DS, Danzig M, Cuss F, Pauwels RA: Effect of SCH55700, a humanized anti-human interleukin-5 antibody, in severe persistent asthma: a pilot study. Am J Respir Crit Care Med 2003, 167:16551659

44. Liu Q, Busby JC, Molkentin JD: Interaction between TAK1-TAB1TAB2 and RCAN1-calcineurin defines a signalling nodal control point. Nat Cell Biol 2009, 11:154-161

45. Ermak G, Harris CD, Battocchio D, Davies KJ: RCAN1 (DSCR1 or Adapt78) stimulates expression of GSK-3beta. FEBS J 2006, 273: 2100-2109
46. Cho YJ, Abe M, Kim SY, Sato Y: Raf-1 is a binding partner of DSCR1. Arch Biochem Biophys 2005, 439:121-128

47. Mehta S, Li H, Hogan PG, Cunningham KW: Domain architecture of the regulators of calcineurin (RCANs) and identification of a divergent RCAN in yeast. Mol Cell Biol 2009, 29:2777-2793

48. Harris CD, Ermak G, Davies KJ: Multiple roles of the DSCR1 (Adapt78 or RCAN1) gene and its protein product calcipressin 1 (or RCAN1) in disease. Cell Mol Life Sci 2005, 62:2477-2486

49. Rothermel BA, Vega RB, Williams RS: The role of modulatory calcineurin-interacting proteins in calcineurin signaling. Trends Cardiovasc Med 2003, 13:15-21 